\title{
Rede social e atenção às pessoas com transtornos mentais: novo desafio para os serviços de saúde mental
}

\author{
Social network and attention to the people with \\ mental problems: new challenge for the mental \\ health services
}

\author{
Juliana de Oliveira Barros ${ }^{1}$, Elisabete Ferreira Mângia ${ }^{2}$
}

\begin{abstract}
BARROS, J. de O.; MÂNGIA, E. F. Rede social e atenção às pessoas com transtornos mentais: novo desafio para os serviços de saúde mental. Rev. Ter. Ocup. Univ. São Paulo, v.18, n. 3, p. 135-142, set./dez. 2007.

RESUMO: Este artigo está baseado nos resultados do projeto de pesquisa "Rede Social e Reabilitação: "RE" Descobrindo o Cotidiano de 3 usuários do Núcleo de Atenção Psicossocial II do Município de Santo André". Teve como objetivo conhecer e descrever as redes sociais de três pessoas com transtornos mentais severos, identificar formas de interação e necessidades das pessoas e por fim, comparar e analisar as redes dos sujeitos estudados. As redes sociais dos sujeitos foram apreendidas a partir do acompanhamento, observação participante, vivência no cotidiano do serviço e entrevistas com familiares. $\mathrm{O}$ estudo confirmou dados da literatura que apontam para a fragilidade das redes sociais de pessoas com transtornos mentais severos e a importância da adoção de estratégias de ativação de redes sociais no contexto do desenvolvimento de projetos assistenciais. Mostrou também os riscos decorrentes das proposições terapêuticas que ao restringirem o sujeito por tempo prolongado no serviço de saúde mental acabam por alimentar o circuito de isolamento e fragilização das redes sociais. Neste contexto, o estudo contribui para a problematização do papel dos serviços substitutivos de saúde mental identificados com as orientações da reabilitação psicossocial.
\end{abstract}

PALAVRAS-CHAVE: Terapia Ocupacional.

\footnotetext{
1. Terapeuta Ocupacional. Mestranda do Programa de Pós-graduação em Ciências da Reabilitação da FMUSP.

2. Prof. Dra. do Departamento de Fisioterapia, Fonoaudiologia e Terapia Ocupacional da FMUSP.

Endereço para correspondência: Departamento de Fisioterapia, Fonoaudiologia e Terapia Ocupacional da FMUSP. Rua Cipotânea, 51. Cidade Universitária. São Paulo, SP. CEP: 05360-160
} 


\section{APRESENTAÇÃO}

$\mathrm{N}$ o Brasil, a Política de Saúde Mental vem buscando construir uma nova perspectiva ética e política de compreensão da experiência da loucura e produzir novas respostas à complexidade e a multidimensionalidade das necessidades que emergiram com a ruptura da tutela asilar. Nos últimos vinte anos este processo tem-se caracterizado pela construção da saúde mental como "território de cidadania, emancipação, reprodução social e qualidade de vida" (NICÁCIO, 2003; MINISTÉRIO DA SAÚDE, 2006). A criação de novos serviços, políticas e projetos locais constituem um dos principais desafios para a efetivação da Reforma Psiquiátrica (NICÁCIO, 2003; MINISTÉRIO DA SAÚDE, 2006).

Nessa direção, partimos do consenso atual de que as variáveis para a obtenção de bons resultados nas intervenções em saúde mental estão mais conectadas a vida dos sujeitos do que à sua doença. Assim, é importante conhecer e refletir sobre suas trajetórias de vida bem como sobre a qualidade dos serviços oferecidos para que haja a possibilidade de aumento de poder contratual dos usuários, a melhoria da qualidade de vida, e a produção de relações capazes de produzir sentido e autonomia (SARACENO, 1999; KINOSHITA, 2001; OMS 2001; MÂNGIA; MURAMOTO, 2007).

Refletindo sobre as novas práticas em saúde mental, Saraceno considera que a reabilitação deve ser um processo de reconstrução e de exercício pleno da cidadania, desenvolvido a partir de três cenários principais. O primeiro está ligado às condições, materiais e afetivas, de apropriação do local onde se mora e dos espaços sociais que se freqüenta. $\mathrm{O}$ segundo se refere à possibilidade de construção de vínculos com a comunidade, família e outros sujeitos considerados importantes, que ofereçam apoio nas diversas situações do cotidiano. E por fim, a possibilidade de validação social quer seja decorrente da produção de mercadorias ou da criação de valores sociais advindos dos diversos níveis de produção (econômica, cultural, simbólica, etc). Nesse sentido a intervenção em saúde mental deve comprometer-se com a restituição do poder contratual e a (re)construção das redes sócio-relacionais dos sujeitos. (SARACENO, 2001, 1999).

Ainda nessa linha de argumentação, a reabilitação só pode estabelecer-se num território que integre estratégias de disponibilização de recursos e acesso aos direitos sociais, de forma a garantir que os sujeitos em desvantagem social, como os que vivenciam a experiência do sofrimento psíquico, possam reconstruir e exercer sua cidadania. (ROTELLI, 1993).
Neste artigo adotamos a premissa de que o processo de reabilitação busca promover mudanças no lugar social tradicionalmente ocupado pelas pessoas com transtornos mentais e para tanto, as intervenções não visam somente os sujeitos, mas o próprio contexto social e as redes sóciorelacionais (SARACENO, 2001).

O estudo das redes sociais nos permite avançar na compreensão de fenômenos relevantes colocados pelas novas estratégias e serviços de saúde (AGUILAR \& MOLINA, 2004). Numa primeira aproximação, rede social pode ser entendida como um "conjunto de relações ou ligações sociais entre um conjunto de atores (e também aos atores ligados entre si)". (EMIRBAYER; GOODWIN, 1994, p. 1449 apud MARTELETO, 2001). Também pode ser compreendida como "multiplicidade quantitativa e qualitativa dos elos entre os seus diferentes membros, orientada por uma lógica associativa" (COLONOMOS, 1995, p. 22-24, apud MARTELETO, 2001),

A saúde foi um dos primeiros campos de aplicação do conceito de rede social. Muitas investigações demonstraram que as redes apresentam-se como importante fator de proteção à saúde, na medida em que constatou-se que indivíduos com redes mais ampliadas e diversas dispõem de melhores níveis de bem estar e qualidade de vida. (KADUSHIN, 1982 apud AGUILAR; MOLINA, 2004).

No contexto da reflexão sobre a importância das redes sociais na prática dos serviços substitutivos em saúde mental e do referencial teórico da Reabilitação Psicossocial este trabalho teve como objetivo geral, conhecer as redes sociais de 3 usuários em tratamento no Núcleo de Atenção Psicossocial II (NAPS II) do Município de Santo André. Buscou também, descrever e mensurar as características das redes sociais dos sujeitos estudados, identificar formas de interação em relação à ajuda (família e serviço) e aos vínculos fortes (família e serviço), identificar necessidades nomeadas pela família, pela própria pessoa e também pelo pesquisador, descrever as ações dos sujeitos no campo relacional, incluindo os aspectos de seu cotidiano e por fim, comparar e analisar as redes dos sujeitos estudados.

Aprovado em 12-04-2006, pela Comissão de Ética para Análise de Projetos de Pesquisa CAPPesq do HCFMUSP, sob protocolo $\mathrm{n}^{\circ} 1255 / 05$, o estudo monográfico foi realizado no período de março a junho de 2006, no contexto da pesquisa intitulada "Estudo Colaborativo sobre a experiência da rede de serviços em saúde mental do municipio de Santo André-SP: caracterizando os serviços, conhecendo resultados e desenvolvendo um experimento sobre a ativação de rede social" (MÂNGIA et al., 2006). As entrevistas foram precedidas de consentimento livre e esclarecido e a pesquisa, desenvolvida após consentimento institucional. 


\section{O processo da pesquisa}

A pesquisa se insere no campo da investigação qualitativa, visto a complexidade e abrangência dos objetivos e objeto estudados que valorizam o "universo de significações, motivos, aspirações, atitudes, crenças e valores" (MINAYO, 1992).

A escolha dos instrumentos e fontes de informação foi criteriosa, levando em consideração a coerência com a estrutura teórico-metodológica, a disponibilidade de acesso aos dados bem como a adequação das características dos indivíduos sob investigação. Os critérios utilizados na seleção dos sujeitos foram: faixa etária entre 20 e 40 anos, estarem em tratamento no NAPS II há pelo menos 6 meses, e disporem de familiares que concordassem em conceder entrevistas.

O acompanhamento do cotidiano dos sujeitos estudados contou com o envolvimento ativo do pesquisador num processo caracterizado como observação participante (VASCONCELOS, 2002). Inserida no contexto da ação assistencial, a coleta de dados possibilitou a observação de aspectos objetivos e subjetivos do cotidiano dos sujeitos e especialmente a interação entre sujeitos e serviço. Foi elaborado um diário de campo, que contemplou o registro e a reflexão sobre a dinâmica, as necessidades e as relações estabelecidas pelos sujeitos (VASCONCELOS, 2002).

As entrevistas com familiares, com caráter focal e circunscrito, foram coletadas em agosto de 2006 (VASCONCELOS, 2002). As categorias de análise foram estabelecidas a partir dos procedimentos iniciais de transcrição, leitura minuciosa e pareamento de conteúdo, de acordo com os objetivos propostos. O material coletado por meio do diário de campo recebeu tratamento semelhante.

\section{Caracterização dos sujeitos}

\section{Sujeito 1}

Nascido em 27 de agosto de 1983, A. S. D., iniciou seu tratamento no NAPS II no mês de março de 2000. Seu prontuário indicava como hipótese diagnóstica Deficiência Mental (F.70 - CID-10) e Psicose Orgânica (F.09 - CID-10). Morava nas proximidades do serviço com os pais (o pai, tinha 60 anos e a mãe 55) e uma irmã (com 21 anos). De acordo com relato da mãe, desde pequeno freqüentou escola especial, tendo participado de oficinas profissionalizantes na APAE. Já em tratamento no NAPS II, freqüentou por pouco tempo um programa escolar e chegou a participar do programa Primeiro Emprego, oferecido pela Prefeitura Municipal de Santo André. No período da coleta de dados
A., não estava inserido em nenhum tipo de programa educacional ou profissional.

No início do acompanhamento, A. havia acabado de perder o direito de receber o Benefício de Prestação Continuada definido pela Lei Orgânica de Assistência Social (LOAS), pois seu pai havia sido empregado no regime de trabalho CLT, o que aumentou a renda da família, ultrapassado o limite de renda permitido para o recebimento do benefício. No final da pesquisa o pai havia sido demitido e a família tentava reaver o beneficio. A renda da família estava em torno de $\mathrm{R} \$ 800,00$.

A mãe relatou haver deixado o emprego de costureira pela necessidade de cuidar de $\mathrm{A}$. A irmã do usuário cursava o supletivo, fazia aulas de reforço escolar e também foi diagnosticada como portadora de deficiência mental leve (F.70 - CID-10).

A. estava em Hospitalidade Noturna - estratégia de atenção utilizada nos serviços substitutivos que possibilita que o usuário durma no serviço - e, permaneceu nesta condição, por aproximadamente dois meses. Posteriormente, foi indicado que A. freqüentasse o serviço de saúde mental todos os dias da semana, exceto aos finais de semana, necessitando, portanto, de atenção intensiva e integral.

\section{Sujeito 2}

Nascida em 8 de dezembro de 1967, V. L. S., iniciou o tratamento no NAPS II no mês de janeiro de 2005. O prontuário indicava como hipótese diagnóstica esquizofrenia (F.20 - CID-10). Residia próxima ao NAPS II e morava com os pais, com idades entre 79 e 80 anos, uma irmã, com 53 anos, que também fazia tratamento em outro serviço de saúde mental, 4 tios (entre 20 e 50 anos) e um sobrinho de 11 anos. Seus pais são primos e V. tem uma irmã, com quadro de Paralisia Cerebral e Convulsões, que reside há 40 anos nas "Casas André Luís". A mãe estava acamada, há cinco anos, devido seqüelas de Acidente Vascular Cerebral.

V. freqüentava o NAPS duas vezes na semana e também estava vinculada ao programa escolar parceiro da instituição. No restante dos dias da semana, trabalhava como vigia de carros no centro de Santo André. Com o dinheiro arrecadado, ajudava no orçamento doméstico e comprava objetos de uso pessoal. No período da pesquisa, V. conseguiu o Benefício de Prestação Continuada. A renda familiar era composta de dois salários mínimos, referentes à aposentadoria dos pais de $\mathrm{V}$.

\section{Sujeito 3}

Nascido em 24 de novembro de 1978, W. C. G., iniciou 
seu tratamento no NAPS II no mês de setembro de 2005. Seu prontuário indicava a hipótese diagnóstica de transtorno afetivo bipolar com componente de agitação psicótica (F.31 - CID-10). Residia próximo ao NAPS II com a mãe (48 anos) e com um irmão (22 anos). Seus pais eram separados. W. estava aposentado e recebendo, do INSS 1 salário mínimo mensal.

De acordo com a mãe, com 7 anos W. apresentou dificuldades escolares, tendo sido transferido para uma escola especial. W. participava do programa escolar e auxiliava uma educadora. Uma vez por semana $\mathrm{W}$. também fazia aulas de teclado e de computação, mas não exercia nenhum tipo de atividade profissional. Freqüentava o NAPS II em regime de tratamento intensivo, ou seja, todos os dias, exceto aos finais de semana.

\section{Análise das redes}

Os dados foram analisados de acordo com o diagrama proposto por Molina (2005). Nele as redes sociais são dispostas em dois círculos concêntricos, que tem o sujeito ao centro. O círculo mais próximo ao sujeito configura seus laços mais íntimos ativos, o segundo círculo as demais relações próximas, que se configuram como a "família estendida", parentes, vizinhança, amigos pessoais e de trabalho. Externamente ao segundo circulo estão as relações mais distantes e ampliadas em relação ao universo familiar.

No caso específico da análise empreendida verificamos que o serviço e seus membros podem ser situados tanto no círculo mais próximo ao sujeito como no circulo intermediário entre as relações mais próximas e familiares e as relações sociais mais ampliadas.

\section{Características das redes, formas de interação e necessidades}

\section{Sujeito 1}

No período da coleta dos dados e acompanhamento de A, destacamos 3 momentos distintos: o primeiro quando estava em hospitalidade noturna, e conseqüente permanência diuturna no Naps. Sua rotina diária esteve restrita ao ambiente institucional, suas relações principais estiveram restritas aos membros da equipe e usuários do serviço. Foi observado que seu círculo mais próximo era composto por 6 funcionários da equipe de manutenção, cozinha, serviços gerais e administração, além dos pais que o visitavam diariamente e o acompanhavam no período noturno. No $2^{\circ}$ circulo encontramos a equipe técnica 2 enfermeiros, o técnico de referência, médico e 1 auxiliar de enfermagem.

No período subseqüente, A. continuou acompanhado em regime de Atenção Intensiva, mas voltou a dormir em sua casa. Nesse período foi observado o aumento dos espaços de circulação social, aumento do contato com os demais membros da família, além de parentes que moravam em seu bairro. Houve também ampliação das relações com os profissionais do serviço decorrente da mudança de médico de referência e a entrada de mais 3 profissionais para auxiliar na condução do caso. No trajeto entre a casa e o serviço, A. interagia com o motorista e o cobrador do ônibus e mantinha relações com a vizinhança. A. era conhecido no bairro e quando encontrado vagando pela rua era aconselhado a retornar para casa. Nesse período o serviço recebeu reclamações de vizinhos sobre o comportamento de A. de sistematicamente ir jogar lixo em um córrego próximo. A família recorria também ao Centro Hospitalar para atendimento de emergências e crises. Houve retorno de A. ao programa escolar e participação em um grupo de atendimento.

No último período, uma nova crise levou a família a optar pela internação em hospital psiquiátrico. Nesse período houve total quebra dos vínculos que vinham sendo preservados; A passou a receber visitas dos pais e eventualmente da irmã.

Sua rede social era muito esvaziada e restrita aos pais e funcionários do serviço. A mãe considerava que o esvaziamento relacional estava diretamente vinculado às características do processo de adoecimento de A., e queixava-se da sobrecarga a ela atribuída. Identificamos que também os profissionais do serviço encontravam muita dificuldade em propor estratégias de cuidado e acompanhar o processo de A., o que gerava uma paradoxal situação de abandono dentro do próprio serviço e excessiva responsabilização aos pais.

A. apresentava muita dificuldade de expressão verbal e consequentemente não formulava claramente suas necessidades. Seus raros pedidos envolveram a vontade de ir de ônibus para o serviço e a solicitação de mais paciência com ele nos momentos de administração de medicamentos.

Já a família explicitava claramente um amplo conjunto de necessidades diante do quadro de A e da sua excessiva dependência aos pais já muito desgastados. Reivindicavam uma ação mais efetiva do serviço em relação à responsabilização sobre a condução do projeto terapêutico do filho. Era evidente a dificuldade do serviço em oferecer à família os suportes de que necessitavam, a continuidade do cuidado e a criação de possibilidades para a inserção social de A. 
A família referia também a necessidade de mudança para uma casa maior que oferecesse mais privacidade a todos, pois a casa onde residiam era pequena e pouco funcional.

Apesar de permanecer a maior parte do tempo no serviço A. não participava de grupos ou oficinas, recebendo apenas consultas médicas; permanecia a maior parte do tempo circulando na instituição. O processo de acompanhamento possibilitou a intensificação dos contatos com A. no tempo que permanecia na instituição e algumas saídas.

Faltava ao serviço à percepção da gravidade do problema enfrentado pela família e sua excessiva responsabilização e isolamento, a importância do estabelecimento de um outro tipo de parceria com a família e o desenvolvimento de um trabalho que propiciasse uma melhor distribuição de responsabilidades e aumento das redes de suporte envolvidas. A situação de A. e de sua família exemplifica os limites das abordagens tradicionais quando se trata de situações complexas e de maior gravidade.

\section{Sujeito 2}

Observamos que V. dispunha de um círculo relacional mais próximo bem denso e composto por familiares, amigos, profissionais, funcionários e usuários do serviço, perfazendo cerca de 15 pessoas. No segundo círculo, também composto por familiares, pessoal do serviço e vizinhança, cerca de 20 pessoas. Por trabalhar na rua tinha relações mais externas bem expandidas embora seja difícil estimá-las.

Sua rede social era um pouco mais ampliada, mas a maior proximidade e responsabilidade também eram compartilhadas por poucos membros da família. O pai assumia o compromisso mais ativo nos cuidados cotidianos e tratamento de V. tendo obtido para ela o benefício de prestação continuada independentemente da ajuda do serviço. Sua irmã mais velha era um dos únicos membros da família que sabia ler e assumia tarefas domésticas além do cuidado com a mãe, que estava acamada em decorrência de acidente vascular cerebral. No serviço V. mantinha bom vínculo com sua técnica de referencia e com seu médico.

V. alimentava grande expectativa sobre a conquista do Benefício de Prestação Continuada, para que pudesse adquirir roupas, objetos pessoais e contribuir com o orçamento familiar. O pai apontava a necessidade de participação de A. nas atividades domésticas, dado o adoecimento da mãe e a sobrecarga da irmã e não aprovava o fato de A. trabalhar na rua. Requeria também o apoio do serviço para a obtenção de cesta básica e recursos específicos para cuidar da esposa acamada a mais de 5 anos, tais como fraldas geriátricas, cadeira de roda etc.
Após a conquista do benefício social, o pai de V. passou a controlar seu acesso aos recursos, pois a considerava pouco capaz de administrar seus gastos. V. carecia de maior apoio na organização de seu cotidiano e cuidados pessoais e de saúde geral e ginecológica, pois dentre outros problemas, sofria com o aumento de peso e desarranjos hormonais, possivelmente decorrentes do uso continuado de neurolépticos.

O processo de acompanhamento possibilitou a percepção sobre o limite do serviço em adotar a perspectiva da integralidade no cuidado destinado a V. A limitação da atenção apenas nos aspectos médico-psiquiátricos e a desresponsabilização sobre os aspectos mais gerais da saúde e sobre o precário contexto familiar de $\mathrm{V}$. nos levaram a um permanente questionamento sobre o papel do serviço na produção de respostas mais efetivas ao processo de vida dessa usuária.

\section{Sujeito 3}

W. mantinha um círculo próximo de relações composto basicamente por familiares, especialmente a mãe e o irmão e pelo pessoal do serviço, especialmente com 5 profissionais, um funcionário administrativo e 2 usuários. No segundo círculo identificamos que $\mathrm{W}$ mantinha contato com os estagiários, uma professora de teclado, uma educadora da qual era auxiliar, freqüentava também a casa de uma tia.

Exteriormente a esses círculos, encontramos relações de vizinhança, pois $\mathrm{W}$ realizava caminhadas no bairro e conhecia algumas pessoas.

Sua rede social era muito restrita e seus vínculos fortes coincidiam com os familiares e profissionais do serviço que o ajudavam, especialmente sua técnica de referência. Embora a mãe, irmão e avó paterna assumissem responsabilidades, era a mãe que ocupava o papel de destaque no tratamento de W. e nas decisões sobre seu projeto terapêutico. Na relação com a mãe era possível identificar aspectos que acabavam por produzir a invalidação de $\mathrm{W}$ e conseqüentemente geradores de sofrimento para ele, tais como: o controle e administração da medicação, a administração da aposentadoria, que era utilizada para pagar as despesas com dentista e as aulas de teclado de W. A mãe guardava o restante para ser utilizado em uma viajem de final do ano, planejada por ela. Um dos grandes objetivos de W. era retomar os estudos e se inserir num programa pré-vestibular. Sua mãe apresentava opiniões ambíguas: ora considerava que o filho deveria se inserir em algum curso profissionalizante e ingressar no mercado de trabalho, ora incentivava-o a retomar os estudos, embora não acreditasse em sua capacidade para cursar a universidade.

Durante o processo de coleta de dados, W. parecia 
perceber o quanto sua vida e seu cotidiano estavam centralizados no serviço de saúde mental. Utilizava esse argumento para justificar sua falta de iniciativa em dar continuidade aos seus projetos de vida.

Notamos que a proposta central dos serviços substitutivos não se cumpria nesse caso. Identificamos que havia extrema dificuldade em trabalhar com os recursos do território de forma a promover o intercâmbio e as trocas sociais que possibilitassem alternativas de inserção social.

Ao invés disso, a proposta de permanência na instituição, por períodos longos de tempo, resultava em um distanciamento dos contatos sociais que dificultava, cada vez mais o retorno à vida cotidiana e produzia o aprisionamento em uma identidade centrada na doença.

\section{Comparação e analise das redes dos sujeitos estudados}

Segundo Molina (2005), as redes sociais são compostas de fenômenos localizados tanto na esfera micro social, mais relacionados às interações entre os sujeitos, quanto na esfera macro social, na qual as redes são configuradas a partir de relações mais estruturadas, que estão imersas, por exemplo, nas instituições. Neste sentido, as redes de apoio social são tradicionalmente constituídas por parentes, amigos e vizinhos, que proporcionam e facilitam a socialização, troca de informação e ajuda em geral.

As redes podem ser analisadas de acordo com suas características, que incluem: o tamanho, o tipo de relação estabelecida, o propósito da relação e a dinâmica. (MOLINA, 2005). Nos casos estudos, $\mathrm{V}$ foi a pessoa que apresentou a rede social de maior tamanho. Avaliamos que o fato dela freqüentar o serviço de saúde mental apenas duas vezes na semana, exercer atividade laborativa e educacional, e consequentemente, não organizar sua vida e seu cotidiano a partir do serviço, como os demais sujeitos estudados, contribui como um fator de proteção contra a fragilização de sua rede social.

Percebemos que V. não estabelecia apenas relações com os familiares, e o fato de trabalhar na rua favorecia o estabelecimento de relações, a troca de informações e socialização, também com outros colegas de trabalho. Em relação à busca de ajuda, recorria principalmente ao seu pai e à sua técnica de referência.

Não foi possível identificar todos os sujeitos, inseridos nas redes sociais de V., que possuem papel ativo, ou seja, que possuem reconhecimento e acessibilidade mútuas (MOLINA, 2005), entretanto, sua situação é a mais favorável dentre os 3 sujeitos estudados.

Se compararmos com a situação de A. observamos que suas relações sociais são compostas, principalmente pela família nuclear já que esta exerce todas as funções que corresponderiam ao conjunto das funções das redes sociais, tais como; auxilio nas situações de emergência, apoio social, socialização, etc. Embora em grau reduzido, o mesmo ocorre na situação de W., pois este possui como membro forte de sua rede social, além da família, uma técnica do serviço de saúde mental.

A observação desses sujeitos confirma o dado apresentado por Molina de que, no caso das minorias, como as populações que vivenciam a experiência do sofrimento psíquico, a participação dos familiares pode chegar a $70 \%$, do total das funções assumidas pelas redes sociais, evidenciando a fragilidade das redes dessas pessoas.

A diversidade das redes pode ser compreendida como indicador de capital social, ou seja, as pessoas que dispõe de diferentes redes sociais, acumulam maior número de recursos disponíveis em sua vida cotidiana (MOLINA, 2005). As diferentes possibilidades de contatos com outras realidades, possibilita também, diferentes recursos, que podem ampliar a contratualidade dos sujeitos e a ocupação de diversos papéis sociais não referidos à doença.

Quando analisamos o perfil econômico dos sujeitos, percebemos que V. e W. possuem melhor disponibilidade financeira, que facilita o acesso à atividades culturais e bens de consumo e se configura enquanto recurso no momento das trocas sociais.

Por outro lado, A. possuía perfil contratual muito reduzido, o que dificultava, na maioria das vezes, o estabelecimento de outras relações, fora da família e do serviço de saúde. Não possuía repertório em relação à forma de se posicionar diante das situações cotidianas e, conseqüentemente, sua possibilidade de intercâmbio com o social tornava-se bastante reduzida.

Verificamos que as redes dos sujeitos estudados possuem uma forte estrutura central, representada principalmente pelas figuras familiares e pelo serviço de saúde mental, que é deslocado para a posição central, especialmente para A. e W. Já a periferia das redes é bastante dispersa e praticamente inexistente nos casos de V. e W.

Segundo Molina (2005), em geral, durante a vida, a média de contatos estabelecidos por uma pessoa está em torno de 290, sendo que acumulam cerca de 3500 contatos, e estabelecem uma forte relação apenas com 18 deles. Verificamos que os sujeitos estudados dispõem de um número bem menor de relações estabelecidas durante a 
vida, principalmente no tocante aos vínculos fortes, o que confirma a situação de grande vulnerabilidade vivenciada por estes sujeitos.

Há aspectos decorrentes do processo de observação que merecem atenção: W. foi o único, entre os três sujeitos estudados, que idealizava planos para seu futuro tanto no campo do trabalho quanto no campo pessoal. Queria casar, ter filhos e constituir sua própria família.

Cada sujeito, de acordo com sua história de vida e sua cultura, demandava um tipo de atenção diferenciada, inclusive em relação às necessidades identificadas tanto pelos familiares quanto pelo pesquisador. Isto reforça a orientação de que os serviços de saúde mental, devem desenvolver projetos terapêuticos singulares, de acordo com as necessidades, desejos e possibilidades de cada sujeito e evitarem as propostas indiferenciadas como aquelas representadas pela excessiva oferta de oficinas ou grupos que muitas vezes ocupam a maior parte do tempo das pessoas sem, no entanto, sustentarem respostas significativas para a melhoria da vida de cada sujeito.

\section{CONSIDERAÇÕES FINAIS}

A reflexão sobre os dados reforça a idéia sobre a necessidade de investimento no fortalecimento das redes sociais, enquanto aspecto central e não secundário, de um plano terapêutico, no contexto das práticas assistenciais em saúde mental. Foi possível verificar que, de fato, os bons resultados na intervenção junto à população com transtornos mentais severos, estão muito mais relacionados ao fortalecimento das redes sociais, do que ao controle dos sintomas ou recaídas, ou ainda no simples desenvolvimento de habilidades.

Neste sentido, durante o processo de construção de projetos terapêuticos é fundamental o desenvolvimento de estratégias que busquem promover mudanças no lugar social ocupado pelas pessoas com transtornos mentais severos e desta forma, as intervenções não deveriam restringir-se somente os sujeitos, mas ao próprio contexto social e as redes sócio-relacionais. (SARACENO, 2001). Concordamos com Saraceno, quando afirma que as intervenções em saúde mental devem ter como eixo principal a construção de vínculos com a comunidade, família e outros sujeitos considerados importantes, e que ofereçam apoio nas diversas situações do cotidiano (SARACENO, 2001, 1999).

O estudo contribuiu para a validação das estratégias que visam aprofundar o conhecimento e a interação com redes sociais de pessoas com transtornos mentais, que além de fazerem parte da construção de projetos terapêuticos, colocam-se, na atualidade, como uma das principais exigências dos novos projetos de Reabilitação Psicossocial.

BARROS, J. de O.; MÂNGIA, E. F. Social network and attention to the people with mental problems: new challenge for the mental health services. Rev. Ter. Ocup. Univ. São Paulo, v.18, n. 3, p. 135142, set./dez. 2007.

ABSTRACT: This article is based on the results of the research project "Rede Social e Reabilitação: "RE" Descobrindo o Cotidiano de 3 usuários do Núcleo de Atenção Psicossocial II do Município de Santo André". It had as objective to know and to describe the social network of three people with severe mental problems, to identify forms of interaction and people necessities and, to compare and analyze the studied citizens' network. The citizens' social network had been apprehended from the accompaniment, participant observation, daily service experience and the interviews with familiar. The study confirmed data from literature that point to the fragility of the social networks of people with severe upheavals mental and the importance of the adoption of social networks activation strategies in the development context of care projects. It also showed the decurrently risks of the therapeutically proposals that when restricting the citizen for an extended time in the service of mental health results for feeding the social networks circuit of isolation and embitterment. In this context, the study contributes to put in doubt the role of the identified substitutes services of mental health with the orientation of the psychosocial rehabilitation.

KEY WORDS: Occupational Therapy. 


\section{REFERÊNCIAS}

AGUILAR, C.; MOLINA, J. L. Redes sociales y antropología: un estudio de caso (discursos étnicos y redes personales entre jóvenes de Sarajevo. Rev. Iberoamer. Filosofía Política Human., Espanhã, v. 7, n. 6, 2004. (Volumen conjunto de REDES y Araucauria).

KINOSHITA, R. T. Contratualidade e reabilitação psicossocial. In: PITTA, A. (org.). Reabilitação psicossocial no Brasil. 2a . ed. São Paulo: Hucitec, 2001. p. 55-59.

MÂNGIA, E. F. Estudo colaborativo sobre a experiência da rede de serviços em saúde mental do município de Santo André - SP: caracterizando os serviços, conhecendo resultados e desenvolvendo um experimento sobre a ativação de rede social. Santo André, 2005.

MÂNGIA, E. F.; MURAMOTO, M. T. Integralidade e construção de novas profissionalidades no contexto dos serviços substitutivos de saúde mental. Rev. Ter. Ocup. Univ. São Paulo, v. 17, n. 3, 2006.

MÂNGIA, E. F.; MURAMOTO, M. T. Redes sociais e construção de projetos terapêuticos: um estudo em serviço substitutivo de saúde mental: Rev. Ter. Ocup. Univ. São Paulo, v. 18, n.1, 2007.

MARTELETO, R.M. Análise de redes sociais - aplicação nos estudos de transferência da informação. Ci. Inf., Brasília, v. 30, n. 1, p. 71-81, 2001.

MINAYO, M. C. S. O desafio do conhecimento. Pesquisa qualitativa em saúde. São Paulo: Hucitec-ABRASCO, 1992.
MOLINA, J. C. El estúdio de las redes personales: contribuciones, métodos y perspectivas. Espanha, 2005.

NICÁCIO, M. F. S. O Desafio da reforma psiquiátrica. In: Utopia da realidade: contribuições da desinstitucionalização para a invenção de serviços de saúde mental. Campinas, 2003. Tese doutorado (Pós Graduação em Saúde Coletiva) Faculdade de Ciências Médicas da Universidade Estadual de Campinas. p. 33-70.

OPAS; OMS. Relatório sobre a saúde no mundo 2001. Saúde Mental. Nova concepção. Nova esperança. Geneva, Suíça, 2001.

ROTELLI, F. Re-Habilitar la re-habilitación. Disponível em: http:// www.exclusion.net/images/pdf/47_comoq_riabilitare_es.pdf. Acesso em: 18 nov. 2006.

SARACENO, B. Libertando identidades: da reabilitação psicossocial à cidadania possível. Tradução de Lúcia Helena Zanetta, Maria do Carmo Zanetta e Willians Valentini. Belo Horizonte: Ed. Te Cora, Instituto Franco Basaglia, 2001.

SARACENO, B. Reabilitação psicossocial: uma estratégia para a passagem do milênio. In: PITTA, A. (org.). Reabilitação psicossocial no Brasil. 2a ed. São Paulo: Hucitec, 2001. p. 13-18, 2001.

VASCONCELOS, E. M. Complexidade e pesquisa interdisciplinar: epistemologia e metodologia operativa. Petrópolis: Vozes, 2002.

Disponível em: http://www.datasus.gov.br/cid10/webhelp/cid10. htm. Acesso em: 26 nov. 2006. 